\title{
Do Privacy and Enjoyment Matter in Personalized Services?
}

\author{
Ilias O. Pappas \\ Department of Informatics \\ Ionian University
}

\author{
Michail N. Giannakos \\ Department of Computer and \\ Information Science \\ Norwegian University of \\ Science and Technology
}

\author{
Vassilios Chrissikopoulos \\ Department of Informatics \\ Ionian University
}

\begin{abstract}
This study integrates personalization, privacy and enjoyment in order to understand customers' intentions to shop online. Results from 168 online customers are presented regarding their privacy concerns and enjoyment that occur from personalized services while shopping online. A structural equation model reveals personalization to affect positively customers' enjoyment and intention to purchase, but has no effect on their privacy concerns. Privacy has a negative effect on both enjoyment and intention to purchase, while enjoyment influences greatly customers' intentions. Enjoyment and privacy have significant roles in forming online behavior when customers use personalized services. This study provides important implications for e-tailers who should always be reminded that when personalized services are offered properly and customers are well informed, not only shopping enjoyment will rise but also privacy concerns will not be affected. The study concludes with directions for future research, such as including emotions and hedonic aspects while investigating personalization.
\end{abstract}

\section{Introduction}

Advances in information technologies give the opportunity to e-tailers to create and offer personalized services. Personalization is used for marketing and advertising purposes in an attempt to communicate in various levels and ways with the customers, and collect data that can and will be used to offer better services. Such data may be transactional, demographic or behavioral and make it a great way to offer personalized services to different customer categories. Online personalized services influence customers' reactions and behavior, making personalization a reliable mean that will lead customers into buying more often. Online personalized environments may affect positively customer's experience and increase his loyalty [1].

Using online personalization e-tailers are able to create strong relations with their customers that will last for a long time. Retaining a customer is much more profitable for a company than finding a new one and keeping a customer happy by satisfying his need increases his intentions to purchase again [2]. Personalization is based on customer's personal information. Hence, the more information a company knows about the customer, the better services it can offer. The goal of every company using such systems is not just to fulfill consumers' needs but also to create needs that the same company will fulfill in time. Therefore, they need to know as much as possible for their customers. Nevertheless, personalization might not always increase customers' continuance intention as different factors affect this relationship. Previous studies have found privacy concerns to affect people in such a significant way, which creates in a negative relation between privacy and purchase behavior [3]. Privacy concerns while shopping online, like the perception of loosing control, are related positively with anxiety and risk, which means less shopping enjoyment for a customer with high privacy concerns [4].

Our paper offers evidence on how personalized services are used in online shopping. We examine if customers that use personalized services develop higher privacy issues, if customers' enjoyment is increased and how customers' intention to shop online is influenced based these services. Moreover, the effect of privacy on enjoyment and intention to purchase is examined, as well as the relation of enjoyment with intention. It is very interesting to study personalization as it may aid in solving the problem of choice; customers who shop online have to choose among a vast number of products. Although personalization technologies have been adopted in electronic commerce over the past years [5], the roles of personalization, enjoyment and privacy together in online shopping are understudied. The objectives of this paper are to investigate how personalization and privacy jointly influence customers' enjoyment, and to examine the importance of the three factors in predicting customer attitudes and behaviors in the context of online shopping. In particular, we developed a research model to examine the relations among personalization, enjoyment and privacy and how every one of these factors influences customers' intention.

The remainder of the paper is organized as follows. In the next section we review the existing literature on personalization, enjoyment, privacy and intention to purchase. In section 3 , we present the 
theoretical foundation of the research model. In section 4, we present the methodology and the measures adopted for collecting data on the online shopping behavior. Section 5 presents the empirical results derived. In the last section of the paper, we discuss the findings and conclude by providing theoretical and practical implications and make recommendations for future research.

\section{Literature Review}

Personalization refers to the ability to provide an individual with specific content and services based on knowledge about his or her preferences and behavior. It also refers to the use of technology and customer information to tailor interactions between online shops and individual customers [6]. Nowadays, personalization has an important role for e-tailers when they plan their strategies regarding the services that they offer. It is important to create a customer relationship that will give them the chance to communicate with the customers directly and personally. Offering personalization in e-commerce means dealing with three problems: identifying a customer, gathering information about the customer, and processing data to create a service, which will be customized for a certain customer (e.g. recommender systems) [7]. This study adopts the definition of Roberts [8], who defines personalization as "the process of preparing an individualized communication for a specific person based on stated or implied preferences" (p.462).

Personalization's goal is to identify and satisfy a special customer or user need. E-commerce, and its transactions which involve selling and buying, is a field of application offered for using personalization methods and techniques. Hence, e-commerce beyond eshops, includes recommendation systems and comparison agents. Previous studies show that personalization influences customers purchase intentions. Lee and Park [2009][9], who study online service personalization attitude, found that it has a positive effect on purchase intention. Website personalization is expected to influence the relation between information content and purchase intention, as depending on the type of information a user receives he or she might consider making a purchase online. Zhang et al. [10] found that individualism and, by extension services based on that, have a significant influence on purchase intention. Moreover Moon et al. [11], try to explain customers' online purchase intention for customized products based on personalization. Their findings indicate that individualism is of major importance when it comes to online customized products and customers' intention to buy them, because such products are tailored to his needs and preferences. The more a customer uses recommendation systems the higher are his purchase intentions.
Over the past years the broad field of personalization has been studied extensively, and Adolphs and Winkelmann [7] provide a vast overview on the subject. Research has focused, among others, on recommender systems [12]. Most recommendation tools ask too much information from the customer, and even though these tools seem like a very good solution to the problems of too much information and too many choices, they are not widely accepted from customers [13]. Particularly, these tools will first ask a number of questions in order to learn the customers' needs and preferences and eventually provide the proper recommendation. However, gathering and using customers' information has a downside; it may be considered as an invasion to the customers' privacy. Information privacy is the ability of the individual to control what personal information are acquired and how they are used. In general, customers on their transactions are expected to choose how much they are willing to share depending on the outcome. The problem of privacy is not about the collection of personal data. Customers do not mind sharing their data if they are to receive services of higher quality, and their privacy is not violated as long as they offer them voluntarily and can control them [4]. The violation occurs when a company does not provide specific privacy policies, hence increasing privacy concerns.

Privacy aspects are very important factors that affect the relationship among customers and e-tailers. Customer' personal data can be collected in two ways; either by directly asking them (explicitly) or by inferring information about them without their knowledge or consent (implicitly). When customers are asked for their personal data they are very likely to share them with the company in order to gain access to the provided service. Although, many companies collect personal data without asking them and customers realize the privacy violation only when the first personalized emails arrive. Previous studies have focused on understanding how customers evaluate their privacy and based on what they decide to trade it for tangible or intangible benefits [14]. Such benefits are those offered through personalization and recommendation tools.

Online shopping experience research has tried to explain how customers' orientations, perceptions and beliefs influence their retail evaluations and behavior. Utilitarian attributes affect and motivate customers' purchases, but with the increase of experience, customers tend to seek hedonic values as well [15]. Utilitarian and hedonic motivation research aims to understand why people shop. Researchers have pointed out the importance of such motivations and have examined them in the context of online shopping along with their effect on online shopping experience [16]. Overall, hedonic and utilitarian motivations aim to incorporate the functional and pleasurable into users' experiences 
and keep users emotionally, cognitively and physically involved in the interaction. Chiu et al. [17], study experienced customers' and found that both utilitarian and hedonic values influence positively their future purchase intentions. This implies that it is important to create a customer relationship, which will in turn offer service providers the opportunity to communicate with their customers on a personalized manner.

In general terms customers enjoy shopping either it is done offline or online. Shopping enjoyment, and by extent enjoyment when receiving personalized services, plays an important role in customers' behavior towards online shopping [18]. Enjoyment, as a hedonic attribute, is related to many types of shopping, while the experience of the shopping procedure is defined by the customers' beliefs and affects the way they feel about it [16]. Some people may shop when they are in a bad mood as they enjoy the process and the result, while others maybe thrilled when they find new deals or acquire products that will make them feel popular.

We argue that is important to examine the relationships among personalization, privacy and enjoyment. Although there are studies that explore the relationship of personalization with some types of emotions (e.g. enjoyment, pleasure), the simultaneous examination of such emotions along with the effects of privacy, while using personalized services, has not been properly addressed. We choose enjoyment, as an important type of emotion and propose that it is essential to understand its relationship with privacy and personalization and their effects on intention to purchase. To achieve this goal, we take into account the effect of personalized services on customers' behavior, their increasing growth over the past few years, the direct effect of enjoyment on customers' attitude and behavior, and the effects of customers' privacy concerns on their emotions and behavior, which have been proved to act as antecedents of negative emotions.

\section{Hypotheses and Model Development}

The aim of the study is twofold. First the study investigates the effect of personalization and privacy together on enjoyment and intention to purchase. Then the importance of personalization, privacy and enjoyment is assessed in predicting customers' behavior while shopping online. In our study, grounded on the view of the literature we adopt the respective constructs and develop the research model.

\subsection{Personalization}

Customers that their ultimate goal is to create a relationship with an online vendor find personalization very imporant. When it comes to online purchases, personalized services aim to aid the customers reach to the right decision by recommending certain products or services, based on his needs, preferences and previous purchases. Consequently, the higher the level of personalization of a recommendation agent the better services it can offer to a customer, because they understand him and his desires in a better way. Also, personalization attitudes, depending on the provided service, have a positive effect on customers' intention to purchase [19]. Taking into account that in order e-tailers to offer personalized services they require a lot of personal and private data from the customer, while their goal is to provide a solution to his problem of choice, the customer may develop mixed emotions towards e-tailers and towards the services that are provided [20]. Previous reseach has found that that customers enjoy shopping online [16]. Liang et al. [21], posit that online vendors expect more positive attitude from their customers when they receive personalized services because personalization inherently evokes positive emotional feelings. Pappas et al. [22] add to this finding as they found personalized services to affect highly customers' enjoyment towards online shopping and create positive attitude towards it. Nevertheless, asking a customer for personal information may lead to privacy violations. Even though $\mathrm{Xu}$ et al. [23] posit that the use of personalized services might override privacy concerns, customers have to choose between their privacy and personalized services, and eventually they have to trade it in order to shop online [14]. Hence, we propose that:

H1: Personalization will have a negative impact on privacy.

H2: Personalization will have a positive impact on enjoyment.

H3: Personalization will have a positive impact on intention to purchase.

\subsection{Privacy}

The privacy paradox in online shopping rests in the fact that the better services the customer wants, based on his needs, desires and preferences, the more personal information he has to reveal. Hwang and Kim [4] argue that web quality with service contents, which includes providing proper privacy information to the customers, has a positive effect on customers' perceived enjoyment. However, as the data are gathered and analyzed automatically, the control people have on this information is highly limited. Using personalization technologies makes it easier and more simple for a company to gather specific data regarding what the customer wants. 
intensity [25]. Moreover, shopping enjoyment has been found to affect customers' behavior [18].

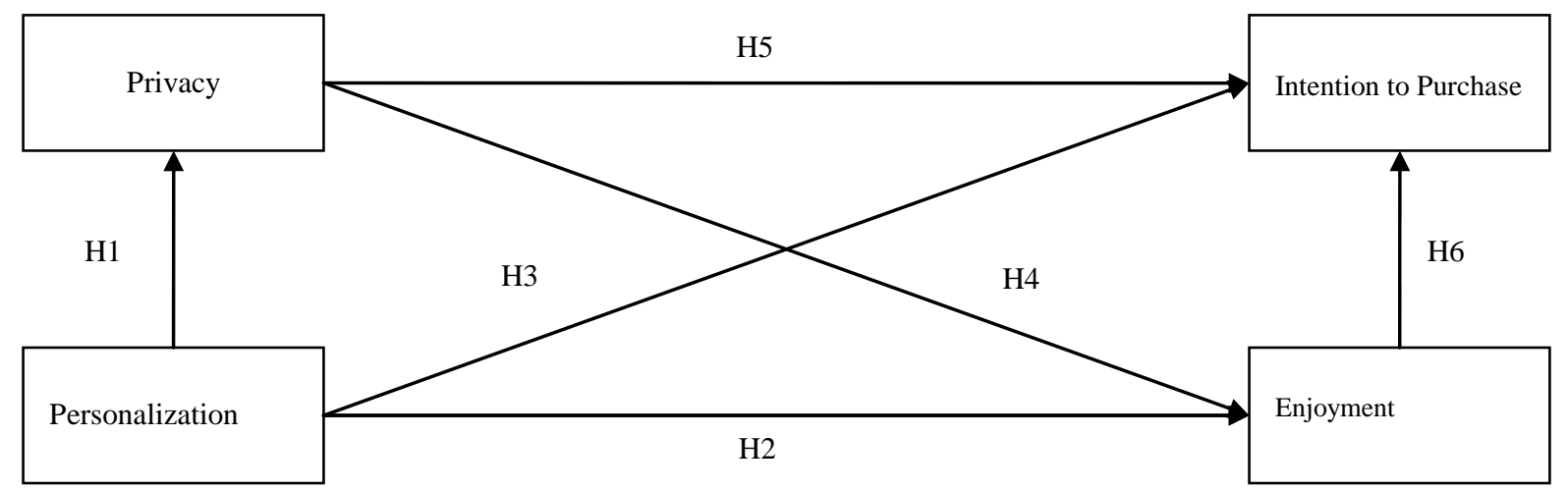

Figure 1. Research Model

The more accurate a company becomes about the personalized services it delivers, the more likely is for the customers' privacy concerns to increase. Previous studies mention that customers feel that their privacy has been violated when they receive recommendations based on previous purchases or even their browsing habits, and those concerns might lead customers to depreciate the advantages of personalization [24]. Consequently, such a violation may diminish the enjoyment that occurs from purchasing online, while high privacy concerns are expected to affect negatively customers' online behavior and attitude. Hence, we propose that:

H4: Privacy will have a negative impact on enjoyment.

H5: Privacy will have a negative impact on intention to purchase.

\subsection{Enjoyment}

Customers shopping online seek both utilitarian and hedonic values (e.g. arousal, fun, pleasure). Various customer emotions arise during consumption and affect their behavior. Pleasure, affects positively customer behavior increasing the chances of a successful purchase. The pleasure that a customer feels when shopping online, affects positively his attitude towards online shopping. As with offline services, customers might develop either positive or negative emotions while using online services. Liang et al. [21] found that personalized services have a high effect on positive emotional feelings, which will lead to a more positive attitude towards online vendors and by extension online shopping. In online shopping, positive emotions are important because they affect customers' future behavior. The enjoyment that a customer feels when shopping online, affects positively his attitude towards online shopping. Previous reseach, investigating hedonic performance in online shopping show that enjoyment has a strong positive effect on online purchase
Hence, we propose that:

H6: Enjoyment will have a positive impact on intention to purchase.

In Fig. 1, we present the research model based on the aforementioned theoretical and empirical research. In addition Fig. 1 clearly states the set of hypotheses that have been formulated and examined in this paper.

\section{Methodology}

\subsection{Sampling}

Our research methodology included a survey conducted through the delivery and collection of individual questionnaires. A number of different methods were recruited for attracting respondents; questionnaires distributed in various places (universities, public areas) and e-mails were sent to different mailing lists. It was made clear that there was no reward for the respondents and the participation was voluntary. The survey was open during the November and December 2011. We aimed at about 600 Greek users of online shopping, 168 of which finally responded.

As Table 1 shows, the sample of respondents was composed of almost equally men (51.2\%) and women $(48.8 \%)$. In terms of age, the majority of the respondents (33.3\%) were between 25 and 29, while the second more frequent age group (27.4\%) involved people between 18 and 24 . Regarding the marital status, most of the respondents $(77.4 \%)$ were single. Finally, the vast majority of the survey respondents $(85.5 \%)$ held a bachelor's or master's degree. 
Table 1. Users' demographic profile

\begin{tabular}{|l|l|l|}
\hline Demographic Profile & No & $\%$ \\
\hline Gender & 86 & $51.2 \%$ \\
Male & 82 & $48.8 \%$ \\
\hline Female & 130 & $77.4 \%$ \\
\hline Marital Status & 33 & $19.6 \%$ \\
Single & 5 & $3 \%$ \\
Married & & \\
\hline Divorced & 6 & $3.6 \%$ \\
\hline Age & 46 & $27.4 \%$ \\
$0-17$ & 56 & $33.3 \%$ \\
$18-24$ & 39 & $23.2 \%$ \\
$25-29$ & 21 & $12.5 \%$ \\
\hline $30-39$ & & \\
$40+$ & 2 & $1.2 \%$ \\
\hline Education & 22 & $13.1 \%$ \\
\hline Middle School & 75 & $44.6 \%$ \\
High School & 69 & $41.1 \%$ \\
\hline University &
\end{tabular}

\subsection{Measures}

The questionnaire was divided into two parts. The first part included questions on the demographics of the sample (age, gender, education). The second part included measures of the various constructs identified in the literature review section. Table 2 lists the operational definitions of the constructs in this theoretical model as well as the studies from which the measures were adopted. The appendix lists the questionnaire items used to measure each construct, along with descriptive statistics and loadings. In all cases, 7-point Likert scales, in which 1 indicates "completely disagree" and 7 "completely agree", were used to measure the model's variables.

Table 2. Construct definition

\begin{tabular}{|c|c|c|}
\hline Construct & Operational Definition & Source \\
\hline $\begin{array}{l}\text { Personalization } \\
\text { (PER) }\end{array}$ & $\begin{array}{l}\text { Tailoring content and services to } \\
\text { match buyers' personal interests or } \\
\text { preferences. }\end{array}$ & {$[23]$} \\
\hline Privacy (PR) & $\begin{array}{l}\text { Measuring customers' privacy } \\
\text { issues when using personalized } \\
\text { services. }\end{array}$ & {$[5]$} \\
\hline $\begin{array}{l}\text { Enjoyment } \\
\text { (ENJ) }\end{array}$ & $\begin{array}{l}\text { Measuring customers' enjoyment } \\
\text { when using personalized services. }\end{array}$ & {$[25]$} \\
\hline \begin{tabular}{|l} 
Intention to \\
Purchase (INT)
\end{tabular} & $\begin{array}{l}\text { Consumers' intention to shop } \\
\text { online based on personalized } \\
\text { services. }\end{array}$ & {$\left[\begin{array}{l}{[26]} \\
{[27]}\end{array}\right.$} \\
\hline
\end{tabular}

\subsection{Data Analysis}

Structural equation modeling was conducted using AMOS version 18.0 software, based on [28]. At first, a measurement model was created based on a confirmatory factor analysis, and then the structural model was built in order to test the hypothesized relationships.
The constructs used in this research were evaluated in terms of reliability and validity. Reliability was examined based on the Cronbach alpha indicator which needs to be higher than 0.7 for every factor. Validation analysis consists of convergent and discriminant validity. Establishing validity requires that Average Variance Extracted (AVE) should be greater than 0.50, the correlation between the different variables in the confirmatory models should not exceed 0.8 points, as this would suggest low discrimination, and that the square root of each factor's average variance extracted (AVE) is larger than its correlations with other factors [28].

Goodness of fit indices describe how well the model fits its data. Here, several fit indices were used to assess model-data fit. Root mean square error of approximation (RMSEA), comparative fit index (CFI) and $\chi^{2} / \mathrm{df}$ ratio were all used to evaluate modeldata fit. RMSEA less than 0.05 suggests good model-data fit; between 0.05 and 0.08 it suggests reasonable model-data fit and between 0.08 and 0.01 suggests acceptable model data fit. CFI indices greater than 0.90 suggest good model-data fit and greater than 0.80 suggest adequate model-data fit. A $\chi^{2} / \mathrm{df}$ ratio less than 3 is acceptable.

\section{Findings}

First, an analysis of reliability and validity was carried out. Reliability testing, based on the Cronbach alpha indicator, as seen on Table 3, shows acceptable indices of internal consistency because they all exceed the cut-off level of 0.70 . Validation testing results can be seen on table 3. AVE for all constructs is higher from the level of 0.50 , all correlations are lower than 0.80 and square root AVEs for all constructs are larger from their correlations.

Table 3. Descriptive statistics and correlations of latent variables

\begin{tabular}{|c|c|c|c|c|c|c|c|c|}
\hline & & & & & \multicolumn{4}{|c|}{ Construct } \\
\hline Construct & Mean & SD & CR & AVE & PER & PR & ENJ & INT \\
\hline PER & 4.65 & 1.6 & 0.922 & 0.803 & 0.897 & & & \\
\hline PR & 5.3 & 1.65 & 0.922 & 0.811 & 0.049 & 0.901 & & \\
\hline ENJ & 4.01 & 1.57 & 0.929 & 0.693 & 0.562 & -0.113 & 30.903 & \\
\hline INT & 4.1 & 1.66 & 0.935 & 0.825 & 0.571 & -0.24 & 0.781 & 0.908 \\
\hline \multicolumn{9}{|c|}{$\begin{array}{l}\text { Note: Diagonal elements (in bold) are the square root of the average variance extracted } \\
\text { (AVE). Off-diagonal elements are the correlations among constructs. For discriminant } \\
\text { validity, diagonal elements should be larger than off-diagonal elements. PER, } \\
\text { Personalization; PR, Privacy; ENJ, Enjoyment; INT, Intention to Purchase. }\end{array}$} \\
\hline
\end{tabular}

The fit indices of the research model are presented on table 4. All values are within the recommended range. Specifically, $\chi^{2} / \mathrm{df}=1.36$, CFI $=0.99$ and $\mathrm{RMSEA}=0.04$. 


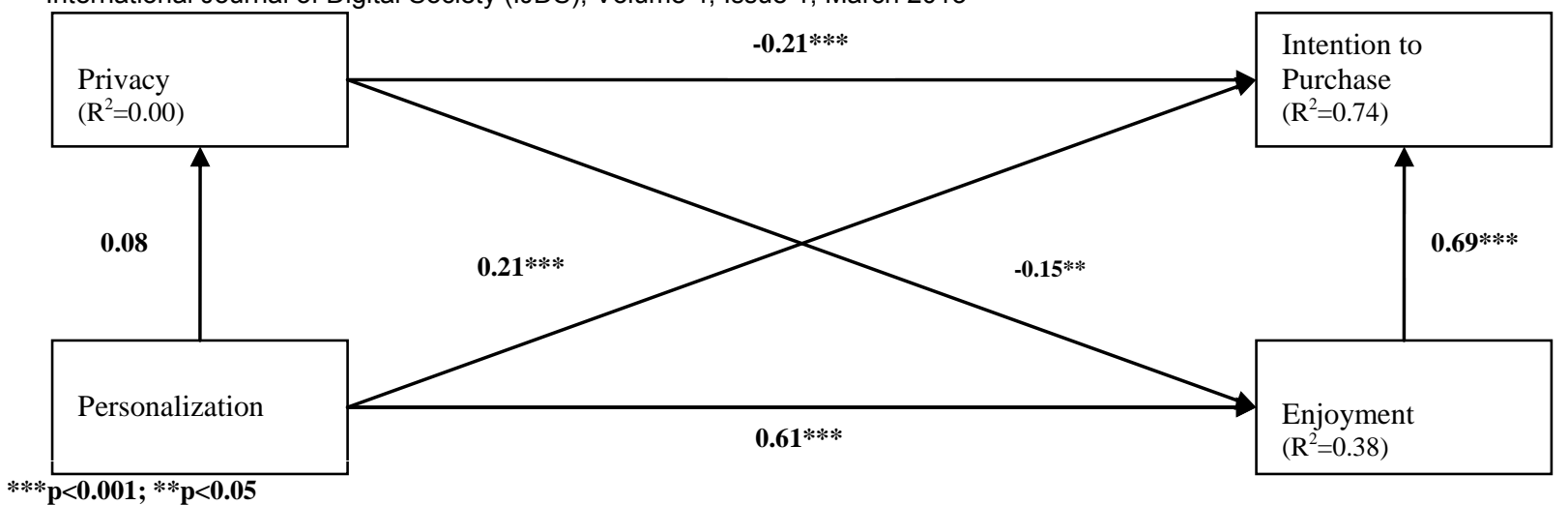

Figure 2. SEM Analysis of the research model

Table 4. Overall model fit indices for the model

\begin{tabular}{|c|c|c|}
\hline $\begin{array}{c}\text { Model fit } \\
\text { indices }\end{array}$ & Results & $\begin{array}{c}\text { Recommended } \\
\text { Value }\end{array}$ \\
\hline$\chi^{2} / \mathrm{df}$ & $\begin{array}{c}1.36 \\
\left(\chi^{2}=65.5 ; \mathrm{df}=48\right)\end{array}$ & $<=0.3$ \\
\hline CFI & 0.99 & $>=0.9$ \\
\hline RMSEA & 0.04 & $<=0.08$ \\
\hline
\end{tabular}

The estimated path coefficients of the structural model were examined in order to evaluate the hypotheses. Figure 2 exhibits the analysis of the research model. The results are as follows. Personalization has a significant effect only on enjoyment and intention to purchase. It affects enjoyment positively, supporting $\mathrm{H} 2$, and intention to purchase positively too, supporting $\mathrm{H} 3$. However, the effect of personalization on enjoyment is three times higher from that on intention to purchase. On the other hand, personalization has no significant effect on privacy, rejecting H1. Regarding the effects derived from privacy, we found that a significant effect on both enjoyment and intention to purchase is presented.

This effect is negative on enjoyment, supporting $\mathrm{H} 4$, and intention to purchase, supporting H5 (with higher significance). Finally, the effect of enjoyment on intention to purchase was found significant as well. In particular, enjoyment has a very high and positive effect on intention to purchase, supporting H6.

Square multiple correlations $\left(\mathrm{R}^{2}\right)$ are presented on figure 2 as well. The $R^{2}$ of privacy was zero as its only predictor had no effect on it. The $\mathrm{R}^{2}$ of enjoyment was 0.38 and that of intention to purchase was 0.74 . Values higher than 0.26 , imply high effect of the predictors of enjoyment and intention to purchase respectively.

\section{Discussion and Conclusions}

This study explored the relations between personalization, privacy, enjoyment and intention to purchase in order to understand customers' intentions towards online shopping. The results indicate that while personalized services do not affect customers' privacy issues, they influence their enjoyment as well as their intention to purchase. In particular, personalization does not influence privacy, but has a positive effect on both enjoyment and intention to purchase. Additionally, privacy was found to have a negative effect on enjoyment and intention to purchase, while enjoyment has a positive effect on intention.

The findings further demonstrate that customers who shop online enjoy more the process if they use personalized services (H2). This may be due to the way these services work, offering the right product at the right time, making the process easier and more enjoyable. Similarly, personalization will raise the intention of customers to shop online (H3), probably because it answers to their needs by providing the right services or products, similar to the findings of [19]. Nevertheless, we found that personalization has no significant effect on the privacy issues of the customers (H1), maybe because when individuals choose to use personalized services they accept and expect some privacy violations, for which they probably have already been informed. This is consistent with the findings of Lee and Cranage [24], who found that in the presence of personalized services, privacy concerns are not affected. Moreover, they showed that when customers are informed properly and assured for their privacy they are willing to share they personal information in order to receive personalized services. This result contradicts with previous studies that have found negative relation between privacy and personalization [29]. Regarding the effects of privacy, it was found to have a negative effect on both enjoyment (H4) and intention to purchase (H5), which was expected as having high privacy concerns, being unwilling to share information while it is the only way to shop online, will reduce the positive feelings that occur when shopping online reducing enjoyment and future intentions. Our findings partially contradict with [4], who found a positive effect of privacy on perceived enjoyment. However, they tested privacy as a part of web quality with service contents and not as a sole factor. Finally, enjoyment has a significant effect on intention to purchase (H6), which was expected because the better a customer feels with a service the more likely he is to use it. Our results concur with 
previous studies, which mention that shopping enjoyment has an important effect on customers' behavior [18]. As such, all our hypotheses except H1 are supported.

Our empirical research has addressed several shortcomings of previous studies in the area. Specifically, Lee and Cranage [24] study the relations between privacy and personalization when the customer reveals willingly his personal information, but do not take into account how that affects his shopping enjoyment. Moreover, Liu and Forsythe [25] examine the effects of enjoyment on online purchasing intensity, but they do not study the effects of privacy issues on enjoyment or online shopping intentions. Lee and Park [19], study the influence of online service personalization on purchase intentions taking into account the effects of subjective norms on customers' attitudes. Nevertheless, they do not measure shopping enjoyment, which is related with subjective norms.

This study is one of the first to include personalization as a predictor variable, while examining its relation with privacy and enjoyment. It also is one of the first to study personalization effects on intention to purchase along with enjoyment and privacy issues. The findings provide useful insights for both practitioners and researchers. Enjoyment is identified as a prime factor that affects online shopping when using personalized services. The results point out the importance of personalization on customers shopping enjoyment, which in turn affects strongly intention to purchase. Hence, providing personalized services is important to increase enjoyment and purchase intentions. Personalization was not found to have a significant effect on privacy issues, adding to the statement that when personalized services are offered properly and the individual is well informed, using such services does not affect his privacy issues. Moreover, online shops should implement personalization tools, which will increase customers' positive emotions such as enjoyment. Nevertheless, the issue remains that with high privacy comes low enjoyment and intention to purchase. Consequently, online shops must include proper and clear privacy policies on their websites, stating the exact use of the collected data, for the customer to decide if he or she will disclose his personal information. We provide evidence that using personalization as an online marketing tool, which will act as it promises without exploiting customers' personal data, will help practitioners to keep their customers happy, which may eventually lead to spending more money and making more purchases. This study also provides evidence that not only personalized services do not dishearten customers but also have no effect on their privacy concerns.

As with any empirical study, there are some limitations. First of all, the empirical data used in this study comprise mostly of Greek online shopping customers. Next, the findings are based on selfreported data; other methods (e.g. depth interviews, observations) could provide a complimentary picture of the findings. Additionally, we only investigate enjoyment while some other aspects of individual emotions, such as anxiety, anger or happiness that have been proved to affect people's behavior were not included in the study. Finally, the majority of our sample is consisted of highly educated individuals, who are expected to be familiar with online services. Further research on these aspects would valuably contribute on the understanding of customers' emotions on personalized services. Both positive and negative emotions should be studied in order to understand if and how their interrelations affect customer behavior. In addition, it would be interesting to see how privacy would affect trust issues towards the online vendors that offer personalized services and if and how intention to purchase leads to actual purchases. Hedonic and utilitarian shopping motivations could be included as well.

\section{References}

[1] Zhou, L., Dai, L., \& Zhang, D. (2007) 'Online shopping acceptance model - A critical survey of consumer factors in online shopping. Journal of Electronic Commerce Research, 8(1), 41-62.

[2] Giannakos, M. N., Pateli, A. G., \& Pappas, I. O. (2011) 'Identifying the Direct Effect of Experience and the Moderating Effect of Satisfaction in the Greek online market', International Journal of E-Services and Mobile Applications (IJESMA), 3(2), 39-58.

[3] Castañeda, J. \& Montoro, F. (2007) 'The effect of internet in general privacy concern on customer behavior' Electronic Commerce Research, 7(2), pp. 117-141.

[4] Hwang, Y. \& Kim, J. D. (2007) 'Customer selfservice systems: The effects of perceived Web quality with service contents on enjoyment, anxiety, and etrust' Decision Support Systems, 43(3), pp. 746-760.

[5] Ho, S. Y. \& Ho, K. K. W. (2008) 'The Effects of web personalization on influencing users' switching decisions to a new website', PACIS 2008 Proceedings. Paper 67.

[6] Adomavicius, G., \& Tuzhilin, A. (2005). Personalization technologies: a process-oriented perspective. Communications of the ACM, 48(10), 8390.

[7] Adolphs, C., \& Winkelmann, A. (2010) 'Personalization Research in E-Commerce-A State of the Art Review (2000-2008)', Journal of Electronic Commerce Research, 11(4), 326-341.

[8] Roberts, R. C., Emotions: An essay in aid of moral psychology, Cambridge University Press, 2003.

[9] Lee, E. J., \& Park, J. K. (2009) 'Online service personalization for apparel shopping', Journal of Retailing and Consumer Services, 16(2), 83-91. 
[10] Zhang, H., Lu, Y., Shi, X., Tang, Z., \& Zhao, Z. (2012) 'Mood and social presence on consumer purchase behaviour in C2C E-commerce in Chinese culture', Electronic Markets, 1-12.

[11] Moon, J., Chadee, D., \& Tikoo, S. (2008) 'Culture, product type, and price influences on consumer purchase intention to buy personalized products online', Journal of Business Research, 61(1), 31-39.

[12] Bo, X. \& Benbasat, I. (2007) 'E-commerce product recommendation agents: Use, characteristics, and impact', MIS Quarterly, 31(1), pp. 137-209.

[13] Murray, K. B. \& Häubl, G. (2008) 'Interactive consumer decision aids', In B. Wierenga (Ed.), Handbook of Marketing Decision Models. New York, NY: Springer Science + Business Media, pp. 55-77.

[14] Tsai, J. Y., Egelman, S., Cranor, L. \& Acquisti, A. (2011) 'The effect of online privacy information on purchasing behavior: an experimental study', Information Systems Research, 22(2), pp.254-268.

[15] Bridges, E., \& Florsheim, R. (2008) 'Hedonic and utilitarian shopping goals: The online experience', Journal of Business Research, 61(4), 309-314.

[16] Close, A. G., \& Kukar-Kinney, M. (2010) 'Beyond buying: Motivations behind consumers' online shopping cart use', Journal of Business Research, 63(9), 986-992.

[17] Chiu, C. M., Wang, E. T. G., Fang, Y. H., \& Huang, H. Y. (2012) 'Understanding customers' repeat purchase intentions in $\mathrm{B} 2 \mathrm{C}$ e-commerce: the roles of utilitarian value, hedonic value and perceived ris', Information Systems Journal (in press).

[18] Ha, S. and Stoel, L. (2009) 'Consumer e-shopping acceptance: Antecedents in a technology acceptance model', Journal of Business Research, vol. 62(5), pp. 565-571.

[19] Lee, E. J., \& Park, J. K. (2009) 'Online service personalization for apparel shopping', Journal of Retailing and Consumer Services, 16(2), 83-91.

[20] Chen, Y. C., Shang, R. A., \& Kao, C. Y. (2009) 'The effects of information overload on consumers' subjective state towards buying decision in the internet shopping environment', Electronic Commerce Research and Applications, 8(1), 48-58.

[21] Liang, T. P., Chen, H. Y., \& Turban, E. (2008) 'Effect of personalization on the perceived usefulness of online customer services: A dual-core theory' In
Proceedings of the 11th International Conference on Electronic Commerce: ACM, pp. 279-288.

[22] Pappas, I. O., Giannakos, M. N., \& Chrissikopoulos, V. (2012) 'Personalized services in online shopping: Enjoyment and privacy', In Proceedings of the 2012 International Conference on Information Society ( $i$ Society), pp. 168-173.

[23] Xu, H., Luo, X. R., Carroll, J. M., \& Rosson, M. B. (2011). The personalization privacy paradox: An exploratory study of decision making process for location-aware marketing. Decision Support Systems, 51(1), 42-52.

[24] Lee, C. H. \& Cranage, D. A. (2011) 'Personalisationprivacy paradox: The effects of personalisation and privacy assurance on customer responses to travel Web sites', Tourism Management, 32(5), pp. 987994.

[25] Liu, C. \& Forsythe, S. (2011) 'Examining drivers of online purchase intensity: Moderating role of adoption duration in sustaining post-adoption online shopping', Journal of Retailing and Consumer Services, 18(1), pp. 101-109.

[26] Chen, Y. T. \& Chou, T. Y. (2012) 'Exploring the continuance intentions of consumers for B2C online shopping: perspectives of fairness and trust', Online Information Review, 36(1), pp. 104-125.

[27] Lu, Y., Cao, Y., Wang, B., \& Yang, S. (2011) 'A study on factors that affect users' behavioral intention to transfer usage from the offline to the online channel', Computers in Human Behavior, 27(1), 355364.

[28] Byrne, B. (2009) 'Structural Equation Modeling with AMOS (Multivariate Applications Series)', Routledge Academic; 2 edition, New York, 2009.

[29] Joinson, A. N. \& Paine, C. B. (2007) 'SelfDisclosure, Privacy and the Internet," In A.N Joinson, K.Y.A McKenna, T. Postmes and U-D. Reips Eds. Oxford Handbook of Internet Psychology, Oxford University Press, pp. 237-252.

\section{Acknowledgements}

The authors wish to thank the respondents to the survey who kindly spent their time and effort in sharing their valuable experience.

\section{Appendix}

\begin{tabular}{llccc}
\hline Measures & Mean & S.D. & Loading \\
\hline Personalization (PER) & & & \\
\hline PER1 & $\begin{array}{l}\text { Online vendors can provide me with personalized deals/ads tailored to } \\
\text { my activity context. }\end{array}$ & 4.72 & 1.69 & 0.84 \\
PER2 & $\begin{array}{l}\text { Online vendors can provide me with more relevant promotional } \\
\text { information tailored to my preferences or personal interests. } \\
\text { Online vendors can provide me with the kind of deals/ads that I might } \\
\text { like. }\end{array}$ & 4.58 & 1.74 & 0.95 \\
PER3 & 1.74 & 0.87 \\
\hline Privacy (PR) & & & 1.78 & 0.76
\end{tabular}




\begin{tabular}{|c|c|c|c|c|}
\hline PR2 & $\begin{array}{l}\text { web behavior. } \\
\text { Personalization causes privacy problems because it may monitor my clicks } \\
\text { and browsing records. }\end{array}$ & 5.27 & 1.79 & 0.97 \\
\hline PR3 & $\begin{array}{l}\text { Personalization causes privacy problems by exposing my personal } \\
\text { information to unknown parties. }\end{array}$ & 5.35 & 1.75 & 0.96 \\
\hline \multicolumn{5}{|c|}{ Enjoyment (ENJ) } \\
\hline ENJ1 & Internet shopping with personalization is enjoyable & 4.26 & 1.61 & 0.92 \\
\hline ENJ2 & Internet shopping with personalization is exciting & 3.84 & 1.68 & 0.89 \\
\hline ENJ3 & Internet shopping with personalization makes me feel good & 3.93 & 1.75 & 0.90 \\
\hline \multicolumn{5}{|c|}{ Intention to Purchase (INT) } \\
\hline INT1 & $\begin{array}{l}\text { In the future I intend to continue shopping online based on personalized } \\
\text { services. }\end{array}$ & 4.29 & 1.74 & 0.92 \\
\hline INT2 & $\begin{array}{l}\text { My general intention to buy online based on personalized services is very } \\
\text { high. }\end{array}$ & 3.95 & 1.81 & 0.94 \\
\hline INT3 & I will shop online in the future based on personalized services. & 4.04 & 1.75 & 0.87 \\
\hline
\end{tabular}

